\title{
SEPARATING TRUE IBNR AND IBNER CLAIMS ${ }^{1}$
}

\author{
By R. SCHNIEPER \\ Winterthur, Switzerland
}

\begin{abstract}
A simple model for IBNR claims is presented. Estimates for the loss reserves and for the ultimate claims rate are derived. Approximations to the mean square error of the estimators are produced. A more specific parametric model is suggested for the case that we deal with claim numbers instead of claim amounts. The general method is illustrated by a practical application to the pricing of a casualty excess of loss cover.
\end{abstract}

\section{INTRODUCTION}

The IBNR Method which we present in this paper has been developed in connection with the pricing of casualty excess of loss covers. The method can also be applied to loss reserving problems for long tail business, however it is best understood in connection with the practical problem which motivated its derivation.

A reinsurer has to quote a price for an excess of loss cover. The statistical information at hand are the revalued individual excess claims from different accident years as well as a revalued measure of the exposure pertaining to each accident year (e.g. the revalued premium income). The problems connected with the revaluation of the claims and of the measure of exposure are by no means trivial. We shall however assume that this revaluation can be performed in a satisfactory way and that our data have been corrected for premium and claims inflation. We shall call this revalued statistics the 'as if' statistics.

To price the cover we have to estimate the ultimate claims amount in the layer, i.e. to perform the IBNR correction. In this paper we present a simple method which requires only about twice the amount of computation of the chain-ladder method and which has the advantage of being practically unbiased. An additional advantage of the estimator defined below is that one can assess its precision. It is felt that these two properties are of special importance when pricing layers with high deductibles where data are scarce.

In the next section we present the general model. In the third section we restrict ourselves to claim numbers. In both these sections we illustrate the

\footnotetext{
1 The Paper has been presented at the XXIth ASTIN Colloquium in New York under the title 'A Pragmatic IBNR Method'.
} 
theory with an extremely simple example. In the last section we apply our method to a practical problem.

\section{THE GENERAL MODEL}

\subsection{Summary statistics}

Most IBNR methods require only one summary statistics: the IBNR triangle. If we have the excess claims from $n$ accident years, the IBNR triangle contains the following information:

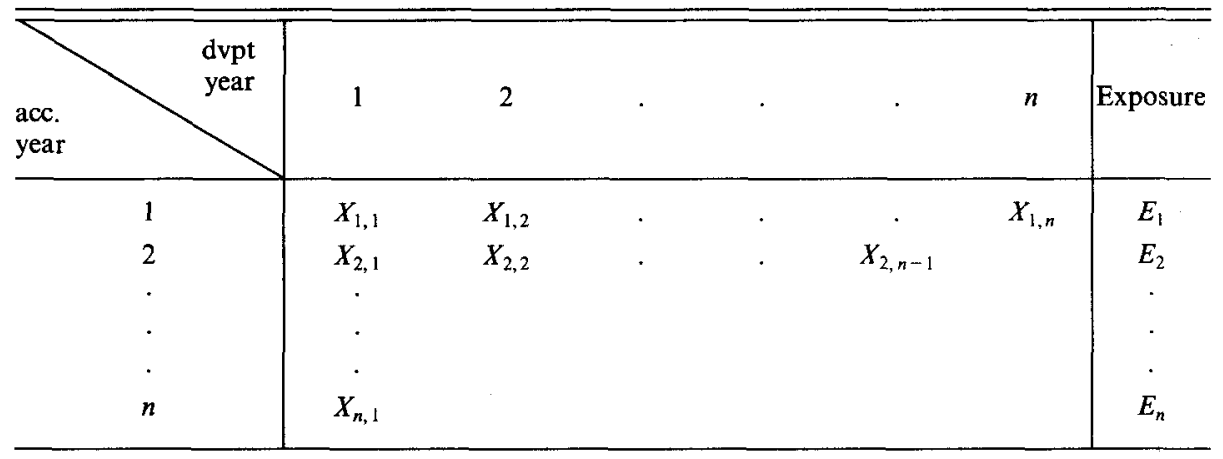

Where $X_{i, j}$ is the total amount of excess claims from accident year $i$ in development year $j$.

For our purposes we need a more detailed summary statistics which we now define. Let $N_{i, j}$ denote the total claims amount pertaining to new excess claims, i.e. to claims which were not yet recorded as excess claims in development year $j-1$. This is the true IBNR component. Let $D_{i j}$ be the decrease in total claims amount between development year $j-1$ and development year $j$ with respect to claims already known as excess claims in development year $j-1$. This is the IBNER component (incurred bu not enough reported claims). $D_{i j}$ may take negative values but cannot by definition be larger than $X_{i, j-1}$.

The following relations hold true between the $X$ 's, $N$ 's and $D$ 's:

$$
\begin{array}{rlrl}
X_{i 1} & =N_{i 1} & i & =1, \ldots n \\
X_{i j} & =X_{i, j-1}-D_{i j}+N_{i j} & i & =1, \ldots n
\end{array}
$$

Of course we only observe the variables for which $i+j \leq n+1$. We shall not as is usually done reduce the data to one IBNR triangle, the $X$-triangle, but we shall work with two triangles: the $N$-triangle of the genuine IBNR claims and the $D$-triangle of the IBNER claims.

From (2.1.1) and (2.1.2) it is seen that the $X$-triangle can be derived from the $N$ - and $D$-triangle.

To illustrate these definitions let us consider a very simple example. 


\section{EXAMPLE}

There are 3 accident years. For each accident year we have the usual 'as if' statistics: revalued and developed individual excess claims as well as a revalued measure of exposure.

\begin{tabular}{|c|c|c|c|c|}
\hline & \multirow{2}{*}{$\begin{array}{l}\text { Claim } \\
\text { number }\end{array}$} & \multicolumn{3}{|c|}{ Development year number } \\
\hline & & 1 & 2 & 3 \\
\hline $\begin{array}{l}\text { Accident } \\
\text { year number } 1 \\
\qquad E_{1}=20\end{array}$ & $\begin{array}{l}1 \\
2 \\
3 \\
4 \\
5 \\
6\end{array}$ & $\begin{array}{l}1 \\
2 \\
- \\
- \\
-\end{array}$ & $\begin{array}{l}- \\
2 \\
0.5 \\
1 \\
1.5 \\
-\end{array}$ & $\begin{array}{l}\overline{1.5} \\
1.5 \\
\overline{2.5} \\
1\end{array}$ \\
\hline $\begin{array}{l}\text { Accident } \\
\text { year number } 2 \\
\qquad E_{2}=25\end{array}$ & $\begin{array}{l}1 \\
2 \\
3 \\
4 \\
5 \\
6\end{array}$ & $\begin{array}{l}0.5 \\
0.5 \\
1.5 \\
- \\
- \\
-\end{array}$ & $\begin{array}{l}\overline{1.5} \\
\overline{0.5} \\
2 \\
1\end{array}$ & \\
\hline $\begin{array}{l}\text { Accident } \\
\text { year number } 3 \\
\qquad E_{3}=32\end{array}$ & $\begin{array}{l}1 \\
2 \\
3 \\
4 \\
5\end{array}$ & $\begin{array}{l}0.5 \\
0.5 \\
1 \\
1.5 \\
2\end{array}$ & & \\
\hline
\end{tabular}

A claim demoted by '- ' ' is a claim which has not yet reached the priority or which has dropped below the priority.

In our example the traditional IBNR triangle is:

\begin{tabular}{|c|c|c|c|}
\hline \multicolumn{4}{|c|}{$X$-triangle } \\
\hline & 1 & 2 & 3 \\
\hline 1 & 3 & 5 & 6.5 \\
\hline 2 & 2.5 & 5 & \\
\hline 3 & 5.5 & & \\
\hline
\end{tabular}

and the new statistics are 
$N$-triangle

\begin{tabular}{|c|c|c|c|}
\hline & 1 & 2 & 3 \\
\hline 1 & 3 & 3 & 1 \\
\hline 2 & 2.5 & 3.5 & \\
\hline 3 & 5.5 & & \\
\hline
\end{tabular}

$D$-triangle

\begin{tabular}{|c|c|c|c|}
\hline & 1 & 2 & 3 \\
\hline 1 & - & 1 & -0.5 \\
\hline 2 & - & 1 & \\
\hline 3 & - & & \\
\hline
\end{tabular}

\subsection{Assumptions}

Let $H_{k}$ denote the set of those variables in the $N$ - and $D$-triangle which are observed up to calendar year $k$ :

$$
H_{k}=\left\{N_{i j}, D_{i j} \mid i+j \leq k+1\right\} .
$$

For the sake of convenience we also introduce:

$$
H_{0}=\{0, \Omega\} .
$$

$H_{n}$ is the set of all variables which have been observed so far. $H_{i+j-2}$ is the history of the process up to the calendar year immediately preceding the emergence of $N_{i j}$ and $D_{i j}$.

We make the following assumptions:

$$
E\left[N_{i j} \mid H_{i+j-2}\right]=E_{i} \lambda_{j} \quad i, j=1, \ldots n
$$

The expected IBNR claims amount does not depend on past history, it is the product of the exposure measure of the accident year with a factor depending on the development year only.

$$
\begin{aligned}
E\left[D_{i j} \mid H_{i+j-2}\right]=X_{i, j-1} \delta_{j} \quad i & =1, \ldots n \\
i & =2, \ldots n
\end{aligned}
$$

The expected decrease in IBNER claims amount is equal to the reported claims amount of the previous development year times a factor depending on the development year.

We only observe those variables for which $i+j \leq n+1$ but for the purpose of loss reserving and rating we shall need the assumptions to hold true for all $i, j=1, \ldots n$.

If we knew whether individual claims are open or closed it might be preferable to replace the $X_{i, j}$ 's in $\left(\mathrm{A}_{2}\right)$ by the corresponding total claims amount pertaining to open claims. 


$$
\begin{aligned}
& \left\{N_{1 j}, D_{1 j} \mid j=1,2, \ldots n .\right\} \\
& \cdot \\
& \cdot \\
& \left\{N_{n j}, D_{n j} \mid j=1,2, \ldots n\right\}
\end{aligned}
$$

are independent sets of random variables. i.e. random variables pertaining to different accident years are stochastically independent.

Assumptions $\left(A_{1}\right),\left(A_{2}\right)$ and $\left(A_{3}\right)$, though they are quite general, are not always satisfied in praxis. In particular, as was remarked by one of the editors, a new claims manager arriving on the scene may have an impact across claims cohorts. In such a case assumption $\left(\mathrm{A}_{3}\right)$ would of course no longer hold true. This I think, shows the limitations of all statistical models and methods used to assess loss reserves: when applying them to practical problems, we should always make sure that we have all the necessary information on the process generating the claims and that we take that information into account when choosing a statistical method to estimate the outstanding losses.

\subsection{Pricing}

We now focus our attention on the pricing problem, i.e. We want to estimate next year's expected excess claim amount $E\left[X_{n+1, n}\right]$ or alternatively next year's expected ultimate claims rate:

$$
R=E\left[\frac{X_{n+1, n}}{E_{n+1}}\right]
$$

If the measure of exposure $E_{n+1}$ is the premium income, then $R$ is the expected ultimate burning cost. Assuming that $\left(\mathrm{A}_{1}\right)$ and $\left(\mathrm{A}_{2}\right)$ hold true for accident year $n+1$, one obtains straightforwardly:

$$
\begin{aligned}
R(\theta)=E\left[\frac{X_{n+1, n}}{E_{n+1}}\right]= & \lambda_{1} \cdot\left(1-\delta_{2}\right) \ldots \cdot\left(1-\delta_{n}\right)+ \\
& \lambda_{2}\left(1-\delta_{3}\right)^{\cdot} \ldots \cdot\left(1-\delta_{n}\right)+ \\
& \cdot \\
& \cdot \\
& \cdot \\
& \lambda_{n-1}\left(1-\delta_{n}\right)+ \\
& \lambda_{n}
\end{aligned}
$$

where

$$
\theta=\left(\lambda_{1}, \ldots \lambda_{n}, \delta_{2}, \ldots \delta_{n}\right)
$$


From $\left(A_{1}\right),\left(A_{2}\right)$ and $\left(A_{3}\right)$ it follows that

$$
\hat{\lambda}_{j}=\frac{\sum_{i=1}^{n+1-j} N_{i j}}{\sum_{i=1}^{n+1-j} E_{i}} \quad j=1, \ldots n
$$

and

$$
\hat{\delta}_{j}=\frac{\sum_{i=1}^{n+1-j} D_{i j}}{\sum_{i=1}^{n+1-j} X_{i, j-1}} \quad j=2, \ldots n
$$

are biasfree estimates of the $\lambda$ 's and $\delta$ 's respectively.

$$
R(\hat{\theta})=\hat{\lambda}_{1}\left(1-\hat{\delta}_{2}\right) \cdot \ldots \cdot\left(1-\hat{\delta}_{n}\right)+\hat{\lambda}_{2}\left(1-\hat{\delta}_{3}\right)^{\cdot} \ldots \cdot\left(1-\hat{\delta}_{n}\right)+\hat{\lambda}_{n}
$$

is an estimate of the ultimate claims rate $R$. The individual estimates being biasfree and the correlation between the factors being 'small' because of $\left(A_{3}\right)$ the bias of $R(\hat{\theta})$ can be neglected.

EXAMPLE (continued)

$$
\begin{array}{cc}
\hat{\lambda}_{1}=\frac{11}{77}=0.143 & \hat{\lambda}_{2}=\frac{6.5}{45}=0.144 \quad \hat{\lambda}_{3}=\frac{1}{20}=0.05 \\
\hat{\delta}_{2}=\frac{2}{5.5}=0.364 & \hat{\delta}_{3}=\frac{0.5}{5}=-0.1 \\
\hat{R}=0.100+0.159+0.050=0.309
\end{array}
$$

\subsection{Loss reserving}

The loss reserve for accident year $i$ is

$$
L_{i}=E\left[X_{\text {in }} \mid H_{n}\right]
$$

Under assumption $\left(A_{1}\right)$ and $\left(A_{2}\right)$ it is easily seen that 


$$
\begin{aligned}
& L_{i}=X_{i, n+1-i}\left(1-\delta_{n+2-i}\right) \ldots \cdot\left(1-\delta_{n}\right) \\
&+E_{i} {\left[\lambda_{n+2-i}\left(1-\delta_{n+3-i}\right) \ldots\left(1-\delta_{n}\right)\right.} \\
&+\lambda_{n+3-i}\left(1-\delta_{n+4-i}\right) \ldots\left(1-\delta_{n}\right) \\
& \cdot \\
& \cdot \\
& \cdot \\
&+\lambda_{n-1}\left(1-\delta_{n}\right) \\
&\left.+\lambda_{n}\right]
\end{aligned}
$$

i.e. the loss reserve consists in a component for IBNER claims and a component for IBNR claims the former depending on the claims observed so far and the latter on the exposure.

One obtains an estimate of $L_{i}$ by replacing the parameters in $(2.2 .6)$ by their estimates (2.2.3) and (2.2.4) respectively.

EXAMPLE (continued)

\begin{tabular}{ccccccc}
\hline \hline $\begin{array}{c}\text { Accident } \\
\text { year } i\end{array}$ & $X_{i, n+1-i}$ & $\boldsymbol{\Delta}_{n+1-i}$ & IBNER $_{i}$ & $E_{i}$ & IBNR $_{i}$ & $L_{i}$ \\
\hline 1 & 6.5 & 1 & 6.5 & 20 & 0 & 6.5 \\
2 & 5 & 1.1 & 5.5 & 25 & 1.25 & 6.75 \\
3 & 5.5 & 0.700 & 3.85 & 32 & 6.67 & 10.52 \\
\hline & 17 & & & & & 23.77 \\
\hline
\end{tabular}

Where $A_{n+1-i}=\left(1-\delta_{n+2-i}\right) \ldots \cdot\left(1-\delta_{n}\right)$ is the IBNER correction factor.

To compute the loss reserves in practice we will of course use the original claims as opposed to the revalued claims used for pricing purposes; we will also have to choose a suitable measure of exposure.

It is interesting to compare (2.2.6) to the formulas for loss reserve provided by the chain-ladder method and by the Bornhuetter-Ferguson method respectively.

The loss reserve for accident year $i$ according to the chain-ladder method is :

$$
L_{i}=X_{i, n+1-i} \cdot F_{n+1-i}
$$

Where $F_{j}$ is some factor pertaining to development year $j$ (for details see for instance Nationale-Nederlanden [2]). The same quantity as estimated by the Bornhuetter-Ferguson method is :

$$
L_{i}=X_{i, n+1-i}+E_{i} \cdot G_{n+1-i}
$$


Where $G_{n+1-i}$ is a factor which is applied to the exposure.

With a suitable notation we can rewrite $(2.2 .6)$ in the following way:

$$
L_{i}=X_{i, n+1-i} \cdot \Delta_{n+1-i}+E_{i} A_{n+1-i}
$$

It is seen that formally our estimator is a generalisation of both the chainladder and the Bornhuetter-Ferguson estimator: $\Delta_{n+1-i}=F_{n+1-i}$ and $A_{n+1-i}=0$ gives the chain-ladder estimator whereas $A_{n+1-\mathrm{i}}=1$ and $A_{n+1-i}=G_{n+1-i}$ gives the Bornhuetter-Ferguson estimator.

\subsection{Performance of the estimator}

We now want to assess the performance of $R(\hat{\theta})$ defined in (2.2.5). In order to do so we need the following stronger assumptions:

$$
\begin{array}{lll}
E\left[N_{i j} \mid H_{i+j-2}\right]=E_{i} \lambda_{j} & & \operatorname{Var}\left[N_{i j}\right]=E_{i} \sigma_{j}^{2} \\
E\left[D_{i j} \mid H_{i+j-2}\right]=X_{i, j-1} \delta_{\mathrm{j}} & \operatorname{Var}\left[D_{i j} \mid H_{n}\right]=X_{i, j-1} \tau_{j}^{2}
\end{array}
$$

Developing $R(\hat{\theta})$ in a Taylor series, we obtain :

$$
R(\hat{\theta}) \simeq R(\theta)+\sum_{i=1}^{2 n-1} \frac{\delta R(\theta)}{\delta \theta_{i}}\left(\hat{\theta}_{i}-\theta_{i}\right)
$$

$\left(\mathrm{A}_{3}\right)$ implies that $\hat{\theta}_{i}$ and $\hat{\theta}_{j}$ are not strongly correlated for $i \neq j$ hence

$$
\operatorname{mse}(R(\hat{\theta}))=E(R(\hat{\theta})-R(\theta))^{2} \simeq \sum_{i=1}^{2 n-1}\left(\left.\frac{\delta R(\theta)}{\delta \theta_{i}}\right|_{\theta=\hat{\theta}}\right)^{2} \operatorname{Var}\left(\hat{\theta}_{i}\right)
$$

where we have replaced the unknown quantities.

$$
\frac{\delta R(\theta)}{\delta \theta_{i}}
$$

by the approximations :

$$
\left.\frac{\delta R(\theta)}{\delta \theta_{i}}\right|_{\theta=\hat{\theta}}
$$

We still have to find approximations for the $\operatorname{Var}\left(\hat{\theta}_{i}\right)$. From $\left(\mathrm{A}_{1}^{\prime}\right),\left(\mathrm{A}_{2}^{\prime}\right)$ and $\left(\mathrm{A}_{3}\right)$ it follows that:

$$
\operatorname{Var}\left(\hat{\lambda}_{j}\right)=\frac{\sigma_{j}^{2}}{\sum_{i=1}^{n+1-j} E_{i}} \quad j=1, \ldots n
$$




$$
\operatorname{Var}\left(\hat{\delta}_{j}\right)=\frac{\tau_{j}^{2}}{\sum_{i=1}^{n+1-j} X_{i, j-1}} j=2, \ldots n
$$

on the other hand we have the following biasfree estimators of $\sigma_{j}^{2}$ and $\tau_{j}^{2}$ respectively

$$
\begin{aligned}
\hat{\sigma}_{j}^{2} & =\frac{1}{n-j} \sum_{i=1}^{n+1-j}\left(N_{i j}-\hat{\lambda}_{j} E_{i}\right)^{2} \frac{1}{E_{i}} & j=1, \ldots n-1 \\
\hat{\tau}_{j}^{2} & =\frac{1}{n-j} \sum_{i=1}^{n+1-j}\left(D_{i j}-\hat{\delta}_{j} X_{i, j-1}\right)^{2} \frac{1}{X_{i, j-1}} & j=2, \ldots n-1
\end{aligned}
$$

and if there are enough development years at hand we have:

$$
\hat{\lambda}_{n}=0 \quad \text { and } \quad \hat{\delta}_{n}=0
$$

and one may assume:

$$
\sigma_{n}^{2}=0 \quad \text { and } \quad \tau_{n}^{2}=0 .
$$

Plugging the expressions given above into (2.3.2) we obtain an approximation for the mean square error of $R(\hat{\theta})$.

EXAMPLE (continued)

$$
\begin{aligned}
& \frac{\delta R}{\delta \lambda_{1}}=\left(1-\hat{\delta}_{2}\right)\left(1-\hat{\delta}_{3}\right)=0.700 \quad \frac{\delta R}{\delta \lambda_{2}}=\left(1-\hat{\delta}_{3}\right)=1.1 \quad \frac{\delta R}{\delta \lambda_{3}}=1 \\
& \frac{\delta R}{\delta \delta_{2}}=-\hat{\lambda}_{1}\left(1-\hat{\delta}_{3}\right)=-0.157 \quad \frac{\delta R}{\delta \delta_{3}}=-\hat{\lambda}_{1}\left(1-\hat{\delta}_{2}\right)-\hat{\lambda}_{2}=-0.235 \\
& \operatorname{Var}\left(\hat{\lambda}_{1}\right)=\frac{\sigma_{1}^{2}}{E_{1}+E_{2}+E_{3}}=48 \cdot 10^{-5} \quad \operatorname{Var}\left(\hat{\lambda}_{2}\right)=\frac{\sigma_{2}^{2}}{E_{1}+E_{2}}=2 \cdot 10^{-5} \\
& \operatorname{Var}\left(\hat{\lambda}_{3}\right)=\frac{\sigma_{3}^{2}}{E_{1}}=0 \\
& \operatorname{Var}\left(\hat{\delta}_{2}\right)=\frac{\tau_{2}^{2}}{X_{11}+X_{21}}=110 \cdot 10^{-5} \quad \operatorname{Var}\left(\hat{\delta}_{3}\right)=\frac{\tau_{3}^{2}}{X_{12}}=0
\end{aligned}
$$

from which one obtains

$$
\mathrm{mse}^{1 / 2}(R(\hat{\theta}))=0.017
$$

Another possibility to evaluate (2.3.3) and (2.3.4) is to specify a parametric model. An example is given in the next section. 


\section{A MODEL FOR CLAIM NUMBERS}

We use the same definitions as in section 2 with the difference that claim amounts are now replaced by claim numbers: $X_{i j}$ denotes the number of excess claims from accident year $i$ in development year $j . D_{i j}$ is the decrease in total number of claims between development year $j-1$ and development year $j$ with respect to claims already known as excess claims in year $j-1$. ( $D_{i j}$ is a non-negative integer smaller or equal to $\left.X_{i, j-1}\right)$. $N_{i j}$ denotes the number of new excess claims pertaining to accident year $i$ in development year $j$. Relations (2.1.1) and (2.1.2) hold true.

\section{EXAMPLE (continued)}

From the individual claims of the example of section 2 we obtain the following IBNR triangle for claim numbers.

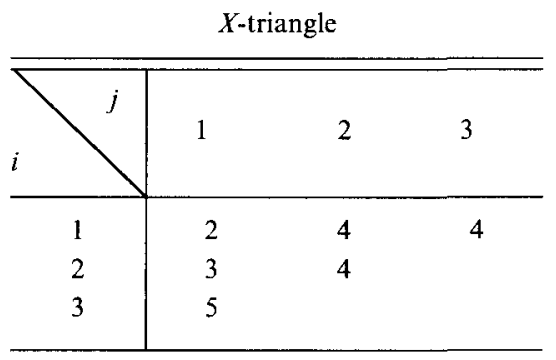

$N$-triangle

\begin{tabular}{l|rrr}
\hline & $j$ & & \\
\hline
\end{tabular}

$D$-triangle

\begin{tabular}{l|lll}
\hline \hline$j$ & 1 & 2 & 3 \\
\hline 1 & & & \\
\hline 1 & - & 1 & 1 \\
3 & - & 2 & \\
\hline
\end{tabular}

Under assumptions $\left(\mathrm{A}_{1}\right)$ and $\left(\mathrm{A}_{2}\right)$ relation (2.2.2) holds true. $R(\theta)$ is now the expected ultimate claims frequency and $\delta_{j}$ is the probability for an excess claim to drop below the priority between development year $j-1$ and development year $j$.

The expressions given in (2.2.3) and (2.2.4) are biasfree estimates of the $\lambda$ 's and $\delta$ 's respectively. (2.2.5) gives an estimate of the ultimate claims frequency $R(\theta)$. The bias of the estimate $R(\hat{\theta})$ can be neglected. 
EXAMPLE (continued)

$$
\begin{array}{cl}
\hat{\lambda}_{1}=\frac{10}{77}=0.130, & \hat{\lambda}_{2}=\frac{6}{45}=0.133, \quad \hat{\lambda}_{3}=\frac{1}{20}=0.05 \\
\hat{\delta}_{2}=\frac{3}{5}=0.6, & \hat{\delta}_{3}=\frac{1}{4}=0.25 \\
R(\theta)=0.189
\end{array}
$$

The performance of $R(\theta)$ can be assessed with (2.3.2).

We now make the following parametric assumptions:

$\left(\mathrm{A}_{1}^{\prime \prime}\right) \quad N_{i j} \mid H_{i+j-2} \sim$ Poisson $\left(\lambda_{\mathrm{j}} \cdot E_{i}\right)$

$\left(\mathrm{A}_{2}^{\prime \prime}\right) \quad D_{i j} \mid H_{i+j-2} \sim \operatorname{Binomial}\left(\delta_{j}, X_{i, j-1}\right)$.

It is easily seen that :

$$
\left(A_{i}^{\prime \prime}\right) \Rightarrow\left(A_{i}^{\prime}\right) \Rightarrow\left(A_{i}\right) \quad i=1,2 .
$$

We also assume that $\left(\mathrm{A}_{3}\right)$ holds true. The log likelihoods of the parameters are:

(3.1) $l\left(\lambda_{j}\right)=-\left(\sum_{i=1}^{n+1-j} E_{i}\right) \lambda_{j}+\left(\sum_{i=1}^{n+1-j} N_{i j}\right) \log \lambda_{j}$

$$
l\left(\delta_{j}\right)=\left(\sum_{i=1}^{n+1-j} D_{i j}\right) \cdot \log \left(\delta_{j}\right)+\left(\sum_{i=1}^{n+1-j} X_{i, j-1}-\sum_{i=1}^{n+1-j} D_{i j}\right) \log \left(1-\delta_{j}\right)
$$

and it is seen, that the $\hat{\lambda}_{j}$ and $\hat{\delta}_{j}$ of (2.2.3) and (2.2.4) are the maximum likelihood estimates of the $\lambda_{j}$ 's and $\delta_{j}$ 's.

From the maximum likelihood theory we know that

$$
\operatorname{Var}\left(\hat{\lambda}_{j}\right) \rightarrow\left[-E\left(\frac{\delta^{2} l}{\delta^{2} \lambda_{j}}\right)\right]^{-1} \quad \text { for } \quad \sum_{i=1}^{n+1-j} E_{i} \rightarrow \infty
$$

we therefore use the following approximations:

$$
\begin{gathered}
\operatorname{Var}\left(\hat{\lambda}_{j}\right) \simeq-\left(\left.\frac{\delta^{2} l}{\delta^{2} \lambda_{j}}\right|_{\lambda=\hat{\lambda}}\right)^{-1} \\
\operatorname{Var}\left(\hat{\lambda}_{j}\right) \simeq \frac{\hat{\lambda}_{j}}{\sum_{i=1}^{n+1-j} E_{i}} j=1, \ldots n
\end{gathered}
$$


analogously:

$$
\operatorname{Var}\left(\hat{\delta}_{j}\right) \simeq \frac{\hat{\delta}_{j}\left(1-\hat{\delta}_{j}\right)}{\sum_{i=1}^{n+1-j} X_{i, j-1}} \quad j=2, \ldots n
$$

and we obtain an approximation of the mean square error of $R(\hat{\theta})$ by plugging (3.3) and (3.4) into (2.3.2).

EXAMPLE (continued)

$$
\begin{aligned}
& \operatorname{Var}\left(\hat{\lambda}_{1}\right)=17 \cdot 10^{-4} \quad \operatorname{Var}\left(\hat{\lambda}_{2}\right)=30 \cdot 10^{-4} \quad \operatorname{Var}\left(\hat{\lambda}_{3}\right)=25 \cdot 10^{-4} \\
& \operatorname{Var}\left(\hat{\delta}_{2}\right)=480 \cdot 10^{-4} \quad \operatorname{Var}\left(\hat{\delta}_{3}\right)=469 \cdot 10^{-4} \\
& \frac{\delta R}{\delta \lambda_{1}}=0.3 \quad \frac{\delta R}{\delta \lambda_{2}}=0.75 \quad \frac{\delta R}{\delta \lambda_{3}}=1 \\
& \frac{\delta R}{\delta \delta_{2}}=-0.097 \quad \frac{\delta R}{\delta \delta_{3}}=-0.185 \\
& \mathrm{mse}^{1 / 2}[R(\hat{\theta})]=0.080
\end{aligned}
$$

\begin{tabular}{|c|c|c|c|c|c|c|c|c|}
\hline $\begin{array}{l}\text { acc. } \\
\text { year }\end{array}$ & 1 & 2 & 3 & 4 & 5 & 6 & 7 & Exposure \\
\hline 1 & 7.5 & 28.9 & 52.6 & 84.5 & 80.1 & 76.9 & 79.5 & $10^{\prime} 224$ \\
\hline 2 & 1.6 & 14.8 & 32.1 & 39.6 & 55.0 & 60.0 & & $12^{\prime} 752$ \\
\hline 3 & 13.8 & 42.4 & 36.3 & 53.3 & 96.5 & & & $14^{\prime} 875$ \\
\hline 4 & 2.9 & 14.0 & 32.5 & 46.9 & & & & $17^{\prime} 365$ \\
\hline 5 & 2.9 & 9.8 & 52.7 & & & & & $19^{\prime} 410$ \\
\hline 6 & 1.9 & 29.4 & & & & & & $17^{\prime} 617$ \\
\hline 7 & 19.1 & & & & & & & $18^{\prime} 129$ \\
\hline
\end{tabular}

4. A PRACTICAL PRICING EXAMPLE

The following IBNR triangle ( $X$-triangle) is borrowed from a practical motor third party liability excess of loss pricing problem:

The excess claims and the measure of exposure (premium of the whole portfolio) have been revalued. Based on these 'as if' statistics we want to estimate the ultimate burning cost.

Using the chain-ladder method we obtain: 


\begin{tabular}{|c|c|c|c|c|c|}
\hline $\begin{array}{c}\text { Accident } \\
\text { year }\end{array}$ & Exposure & $\begin{array}{c}\text { Total } \\
\text { Claims } \\
\text { Amount } \\
\text { per dvpt } \\
\text { year } \\
n+1-i\end{array}$ & $\begin{array}{c}\text { Cumulative } \\
\text { Factor }\end{array}$ & $\begin{array}{c}\text { Estimated } \\
\text { Ultimate } \\
\text { Claims } \\
\text { Amount }\end{array}$ & $\begin{array}{c}\text { Estimated } \\
\text { Ultimate } \\
\text { Burning } \\
\text { Cost }\end{array}$ \\
\hline 1 & $10^{\prime} 224$ & 79.5 & 1 & 79.5 & $0.78 \%$ \\
\hline 2 & $12^{\prime} 752$ & 60 & 1.03 & 62 & $0.49 \%$ \\
\hline 3 & $14^{\prime} 875$ & 96.5 & 1.05 & 101.1 & $0.68 \%$ \\
\hline 4 & $17^{\prime} 365$ & 46.9 & 1.37 & 64 & $0.37 \%$ \\
\hline 5 & $19^{\prime} 410$ & 52.7 & 2.00 & 105.3 & $0.54 \%$ \\
\hline 6 & $17^{\prime} 617$ & 29.4 & 3.75 & 110.2 & $0.63 \%$ \\
\hline \multirow[t]{2}{*}{7} & $18^{\prime} 129$ & 19.1 & 17.07 & 326.0 & $1.80 \%$ \\
\hline & $110^{\prime} 372$ & & & 848.3 & $0.77 \%$ \\
\hline
\end{tabular}

(For details on the chain-ladder method see for instance Nationale-Nederlanden [2]).

It is seen at once that the estimated ultimate burning cost pertaining to accident year 7 is much larger than the other estimated burning costs. This is due to a well known problem inherent to the chain-ladder method: the claims amount of the least developed accident year is multiplied with the largest cumulative factor providing thus a very imprecise estimate which can heavily influence the overall ultimate burning cost. This drawback of the chain-ladder method can easily be corrected by weighing the estimated ultimate burning costs of the individual accident years in a different way. Let $F_{j}$ denote the cumulative factor provided by the chain-ladder method which is to be applied to the claims amount of development year $j . X_{i j}, E_{i}$ and $R$ denote respectively the total claims amount, the exposure and the ultimate burning cost as defined in section 2 . The estimated ultimate burning cost pertaining to accident year $i$ is then:

$$
\frac{X_{i, n+1-i} \cdot F_{n+1-i}}{E_{i}}
$$

The chain-ladder method weighs these estimates with $E_{i}$ the exposure of the corresponding accident year, thus giving the following overall estimated ultimate burning cost

$$
R=\frac{\sum_{i=1}^{n} X_{i, n+1-i} \cdot F_{n+1-i}}{\sum_{1=i}^{n} E_{i}}
$$

Instead of $E_{i}$ we use the following weights:

$$
\frac{E_{i}}{F_{n+1-i}}
$$


which correspond to 'used exposure' and give less weight to less developed accident years.

We obtain the following overall estimated burning cost:

$$
R=\frac{\sum_{i=1}^{n} X_{i, n+1-i}}{\sum_{1=i}^{n} \frac{E_{i}}{F_{n+1-i}}}
$$

We have the thus rederived a special case of the Cape Cod method [3], an IBNR method similar to the Bornhuetter-Ferguson method [1]. This method provides the following estimates:

\begin{tabular}{|c|c|c|c|c|c|}
\hline $\begin{array}{l}\text { Accident } \\
\text { year }\end{array}$ & Exposure & $\begin{array}{c}\text { Total } \\
\text { Claims } \\
\text { Amount } \\
\text { as per } \\
\text { dvpt year } \\
n+1-i\end{array}$ & $\begin{array}{c}\text { Cumulative } \\
\text { Factor }\end{array}$ & $\begin{array}{c}\text { 'Used } \\
\text { Exposure' }\end{array}$ & $\begin{array}{c}\text { Estimated } \\
\text { Ultimate } \\
\text { Burning } \\
\text { Cost }\end{array}$ \\
\hline 1 & $10^{\prime} 224$ & 79.5 & 1 & $10^{\prime} 224$ & $0.78 \%$ \\
\hline 2 & $12^{\prime} 752$ & 60 & 1.03 & $12^{\prime} 335$ & $0.49 \%$ \\
\hline 3 & $14^{\prime} 875$ & 96.5 & 1.05 & $14^{\prime} 199$ & $0.68 \%$ \\
\hline 4 & $17^{\prime} 365$ & 46.9 & 1.37 & $12^{\prime} 697$ & $0.37 \%$ \\
\hline 5 & $19^{\prime} 410$ & 52.7 & 2.00 & $9^{\prime} 712$ & $0.54 \%$ \\
\hline 6 & $17^{\prime} 617$ & 29.4 & 3.75 & $4^{\prime} 698$ & $0.63 \%$ \\
\hline \multirow[t]{2}{*}{7} & $18^{\prime} 129$ & 19.1 & 17.07 & $1^{\prime} 062$ & $1.80 \%$ \\
\hline & & 384.1 & & $64^{\prime} 928$ & $0.59 \%$ \\
\hline
\end{tabular}

We now consider the more detailed statistics of the $N$ - and $D$-triangles. The statistics of new IBNR claims are:

\begin{tabular}{|c|c|c|c|c|c|c|c|}
\hline $\begin{array}{l}\text { acc. } \\
\text { year }\end{array}$ & 1 & 2 & 3 & 4 & 5 & 6 & 7 \\
\hline 1 & 7.5 & 18.3 & 28.5 & 23.4 & 18.6 & 0.7 & 5.1 \\
\hline 2 & 1.6 & 12.6 & 18.2 & 16.1 & 14.0 & 10.6 & \\
\hline 3 & 13.8 & 22.7 & 4.0 & 12.4 & 12.1 & & \\
\hline 4 & 2.9 & 9.7 & 16.4 & 11.6 & & & \\
\hline 5 & 2.9 & 6.9 & 37.1 & & & & \\
\hline 6 & 1.9 & 27.5 & & & & & \\
\hline 7 & 19.1 & & & & & & \\
\hline
\end{tabular}

$N$-triangle 
The statistics of decreases in the claims amount are:

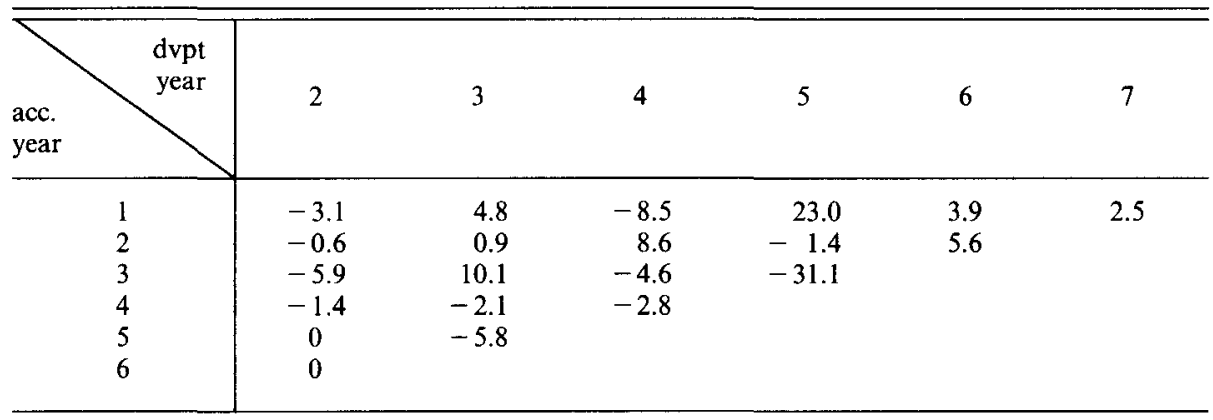

$D$-triangle

The striking feature of these more detailed statistics is that even in development year 6 and 7 there is an important amount of new claims to the layer, however this fact is partly compensated by a decrease of the amount of already known excess claims and therefore the less detailed traditional IBNR statistics give the spurious impression that the total amount of excess claims is exactly known after six or seven development years which is obviously not the case in this example.

We now want to estimate the ultimate burning cost with our method. From (2.2.3) and (2.2.4) we obtain:

\begin{tabular}{ccr}
\hline$j$ & $\hat{\lambda}_{j}$ & \multicolumn{1}{c}{$\hat{\delta}_{j}$} \\
\hline 1 & $0.45 \cdot 10^{-3}$ & \\
2 & $1.06 \cdot 10^{-3}$ & -0.359 \\
3 & $1.40 \cdot 10^{-3}$ & 0.072 \\
4 & $1.15 \cdot 10^{-3}$ & -0.048 \\
5 & $1.18 \cdot 10^{-3}$ & -0.054 \\
6 & $0.49 \cdot 10^{-3}$ & 0.070 \\
7 & $0.50 \cdot 10^{-3}$ & 0.033 \\
\hline
\end{tabular}

We see that the $\hat{\lambda}$ 's reach a maximum in year 3 and decrease thereafter but it would be misleading to assume that $\lambda_{j}=0$ for $j \geq 8$.

Between the 1st and the 2nd development year there is an important increase of the known excess claims; after that the excess increase or decrease more or less randomly and the $\hat{\delta}$ 's oscillate around zero.

By plugging the parameters into (2.2.5) we obtain the following estimate for the ultimate burning cost :

$$
R(\hat{\theta})=0.61 \%,
$$

An estimate which is almost identical to the one obtained with the Cape Cod method. 
Under assumptions $\left(\mathrm{A}_{1}\right),\left(\mathrm{A}_{2}\right)$ and $\left(\mathrm{A}_{3}\right)$ we know that $R(\hat{\theta})$ is a practically biasfree estimate of $R(\theta)$, whereas neither in the case of the chain-ladder estimate nor in the case of the Cape Cod estimate do we know anything about the bias of the estimator.

We now make the stronger assumptions $\left(\mathrm{A}_{1}^{\prime}\right),\left(\mathrm{A}_{2}^{\prime}\right)$ and $\left(\mathrm{A}_{3}^{\prime}\right)$ and we estimate $\sigma_{j}$ and $\tau_{j}$ according to (2.3.5) and (2.3.6).

\begin{tabular}{lll}
\hline \hline$j$ & $\hat{\sigma}_{j}$ & $\hat{\tau}_{j}$ \\
\hline 1 & 0.054 & \\
2 & 0.074 & 0.387 \\
3 & 0.109 & 1.269 \\
4 & 0.079 & 1.177 \\
5 & 0.056 & 3.460 \\
6 & 0.057 & 0.303 \\
7 & 0 & 0 \\
\hline
\end{tabular}

The assumption $\hat{\sigma}_{7}=0$ and $\hat{\tau}_{7}=0$ is not very realistic, however it has little impact on the mean square error of $R(\hat{\theta})$. From (2.3.3) and (2.3.4) we now obtain the standard deviations of the estimators of our parameters.

\begin{tabular}{lll}
\hline$j$ & $\sigma\left(\hat{\lambda}_{j}\right)$ & $\sigma\left(\hat{\delta}_{j}\right)$ \\
\hline 1 & $0.16 \cdot 10^{-3}$ & \\
2 & $0.24 \cdot 10^{-3}$ & 0.070 \\
3 & $0.40 \cdot 10^{-3}$ & 0.121 \\
4 & $0.34 \cdot 10^{-3}$ & 0.095 \\
5 & $0.29 \cdot 10^{-3}$ & 0.260 \\
6 & $0.38 \cdot 10^{-3}$ & 0.026 \\
7 & 0 & 0 \\
\hline
\end{tabular}

We also need the following expressions:

$$
\begin{array}{lll}
\frac{\delta R}{\delta \lambda_{1}}=\Delta_{1}=1.253 & \frac{\delta R}{\delta \lambda_{2}}=\Delta_{2}=0.921 & \frac{\delta R}{\delta \lambda_{3}}=\Delta_{3}=0.993 \\
\frac{\delta R}{\delta \lambda_{4}}=\Delta_{4}=0.948 & \frac{\delta R}{\delta \lambda_{5}}=\Delta_{5}=0.899 & \frac{\delta R}{\delta \lambda_{6}}=\Delta_{6}=0.967 \\
\frac{\delta R}{\delta \lambda_{7}}=1 & \\
\frac{\delta R}{\delta \delta_{2}}=-\lambda_{1} \Delta_{1} \frac{1}{1-\delta_{2}}=-0.00041 & \frac{1}{\delta R}=-\left[\lambda_{1} \Delta_{1}+\lambda_{2} \Delta_{2}\right] \frac{1}{1-\delta_{3}}=-0.00166
\end{array}
$$




$$
\begin{aligned}
& \frac{\delta R}{\delta \delta_{4}}=-\left[\lambda_{1} \Delta_{1}+\lambda_{2} \Delta_{2}+\lambda_{3} \Delta_{3}\right] \frac{1}{1-\delta_{4}}=-0.00279 \\
& \frac{\delta R}{\delta \delta_{5}}=-\left[\lambda_{1} \Delta_{1}+\ldots+\lambda_{4} \Delta_{4}\right] \frac{1}{1-\delta_{5}}=-0.00381 \\
& \frac{\delta R}{\delta \delta_{6}}=-\left[\lambda_{1} \Delta_{1}+\ldots+\lambda_{5} \Delta_{5}\right] \frac{1}{1-\delta_{6}}=-0.00546 \\
& \frac{\delta R}{\delta \delta_{7}}=-\left[\lambda_{1} \Delta_{1}+\ldots+\lambda_{6} \Delta_{6}\right] \frac{1}{1-\delta_{7}}=-0.00574
\end{aligned}
$$

From (2.3.2) we now obtain

$$
\mathrm{mse}^{1 / 2}(R(\hat{\theta})=0.13 \%)
$$

Our method also provides a measure of the precision of the point estimator.

To summarize what we have obtained so far we can say that we have an estimate of the burning cost after seven development years $(0.61 \%)$, this estimate is practically unbiased and reasonably precise since its standard deviation is $(0.13 \%)$. Our detailed statistics have shown us that there are still some excess claims to be expected in the following development years, a fact which we would have overlooked if we had only used the usual IBNR statistics. To assess the impact of further development years on the ultimate burning cost we can use the experience of similar portfolios or some market statistics if that kind of data is available, if such is not the case we can extrapolate our estimates of the $\lambda$ 's and of the $\delta$ 's.

Based on the analysis of the given portfolio, a realistic extrapolation would be:

$$
\begin{aligned}
& \lambda_{8}=\lambda_{9}=0.5 \cdot 10^{-3} \\
& \lambda_{j}=0 \quad j=10,11 \ldots \\
& \delta_{j}=0 \quad j=8,9, \ldots
\end{aligned}
$$

Thus our estimate of the ultimate burning cost is

$$
R=0.71 \% \text {. }
$$

\section{REFERENCES}

[1] Bornhuetter, R.L. and Ferguson, R. E. (1972) The Actuary and IBNR. Proceedings of the Casualty Actuarial Society LIX, 181-195.

[2] Loss Reserving Methods. Surveys of Actuarial Studies No 1, a publication of the NationaleNederlanden N.V., 1981.

[3] Straub, E. (1988) Non-Life Insurance Mathematics. Springer Verlag.

\section{R. SCHNIEPER}

'Winterthur' Swiss Insurance Company, Rudolfstr. 1, P.O. Box 286, CH-8401 Winterthur, Switzerland. 